is unfortunate, as a logically acceptable determination of $e$ is really one of the keystones of an undogmatic and experimental approach to the teaching of modern physics at an elementary level.

The high standard of writing and illustration of the earlier editions has been maintained, and the book can be recommended as a stimulating source of information for the school library.

G. R. NOAKES

\section{VACUUM TECHNIQUE}

\section{An Introduction to Vacuum Technique}

By A. H. Turnbull, R. S. Barton and Dr. J. C. Riviere. (Newnes Practical Seience Books.) Pp. $x+190$. (London: George Newnes, Ltd., 1962.) 50s. net.

N the proface to this volume the authors explain that 1 the book grew from a report of the Atomic Energy Research Establishment entitled Vacuum Technique for Beginners and written in 1951. That this book is still eminently suitable for beginners in the field of vacuum technology is evident, since it is written in a concise, economical style and in easily readable language. However, as most vacuum technologists are aware, major advances in vacuum science have occurred in the past decade, and recognizing this, the authors have included a great deal of material describing this recent knowledge. This work, therefore, becomes an up-to-date introduction and will find a welcome place on many library shelves or, what is more likely, on many laboratory benches.

The book commences with a very adequate analysis of the kinetic theory necessary to an understanding of vacuum systems and components. This chapter is particularly meritorious since the mathematics are lucidly presented and unnecessary detail is avoidod. However, in view of the factors which limit the attainment of ultra-high vacuum (for example, desorption, surface migration, otc.) it is felt that this chapter could have been usefully improved by a short discussion of the concept of the sticking time of molecules to surfaces with emphasis on the importance of desorption energies and surface temperatures.

The second chapter, which follows naturally, applies the results obtained in the previous section to the calculation of conductances of components normally oncountered in vacuum systems (a very useful calculation of the conductance of a cold trap is included). An introduction to the chapter on pumps, in the way of definition of pumping speed and the limitations on the vacuum obtained would be a great improvement, but apart from this the topic is handled efficiently. Examples of the topicality of the book are found in a description of a triode sputter ion pump (which is still very much in the experimental stage) and in a very complete analysis of refrigerated and unrefrigerated vapour traps.

A debate of the hoary question, 'oil or mercury diffusion pumps', is also treated in a competent manner and should help to clear up misunderstandings in the minds of many users of these devices.

In view of the statement on the cover of the book that the contents deal largely with branches of the subject with which the authors have considerable experience, it is unusual to find that the chapter on vacuum gauges does not include a description of mass spectrometers. In many applications a knowledge of the individual gas components in a system, in addition to the total pressure, is mandatory, and the many commercially available gas analysers testify to this need. It is hoped that the authors may have an opportunity to rectify this omission, which detracts from the value of this chapter, in a future edition. The table of the ranges of various vacuum gauges also would be more valuable if the gauges capable of measuring pressures less than $10^{-8}$ torr were included (for example, Bayard-Alpert, Lafferty, Redhead gauges) although to be fair these are adequately described in the text. The materials used in vacuum systems and the techniques used in coupling of components, isolation, etc., are given admirable coverage and the comparison of various types of gaskets is conducted objectively. The descriptions of hydrogon brazing and argon arc welding are also commendable.

The design of vacuum systems and their associated protection devices is also treated in some dotail, but here again the concept of molecular sticking times would be advantageous in discussing the necessity of baking ultrahigh vacuum systems. Finally, the chapter on leak detection gives comprehensive coverage of this topic and concludes with the observation that care must be taken when choosing a commercial mass spectromoter leakdetector since many manufacturers quote only a minimum dotectable leak rate. Of eourse, the parameter of importance in leak detection is the minimum pressure change detectable by the instrument, and in order to convert quoted leak rates to this paramoter full knowledge of the instrumental pumping speed must be available.

To conclude, this book fills a gap between the highpriced rather bibliographical texts, several of which are now available, and some smaller less up-to-date works. Explanatory illustrations are numerous and the references aro very adequate. There will be a demand for this text in many laboratories, both by research workers who use ovacuation as a tool and by design technicians. The book should also commend itself to undergraduate physics and engineering students, as an authoritative survey of present tochniques in the production and moasurement of all degrees of vacuum. G. CARTER

\section{QUANTUM THEORY}

\section{Quanta and Reality}

A Symposium (Nuffield Foundation Unit for the History of Ideas), originally broadcast in the BBC Third Programme. Contributions by Prof. A. B. Pippard, Prof. N. Kemmer, Dr. Mary B. Hesse, Prof. M. Pryce, Prof. D. Bohm and Prof. N. R. Hanson. Pp. 96 (3 plates). (London: Hutchinson and Co. (Publishers), Ltd., 1962.) $18 s$.

[HIS symposium describes and criticizes the conceptua] background and some technical achievements of modern quantum theory. A.fter a historical introduction by Dr. Toulmin, Prof. Pippard, in "Particles and Waves", gives a vivid account of basic ideas in electron diffraction, energy quantization in atoms, and radioactive decay. Prof. Kemmer follows, in "Waves and Probability", with a careful discussion of the kind of knowledge which is attainable for electrons, etc., the uncertainty principle, and the particle-wave duality in quantum theory. In "Models and Matter" Dr. Hesse assessos the significance of models of physical entities with 'positive' analogies and 'negative' analogies. In a discussion Prof. Pryce, while wishing orthodoxy to be open always to free criticism, emphasizes the importance of a theory which makes reasonably precise calculations and comparison with experiment possible, while his opponent Prof. Bohm makes philosophical objections and wishes to amplify the conceptual content of theory but proposes no possible experiment which will show that his ideas are physically preferable to the more usual ones. Finally Prof. Hanson summarizes, gives what seems to me a misleading account of 'renormalized' theory, but comes down in favour of a 'working' theory, while waiting for alternative speculations to reach a less vague form.

To cite one or two sentonces which seem to me to bo historically misleading, wrong, or physically correct but confusing, for example, "its velocity is one of a whole range of possible velocities", would be to dotract unjustifiably from the virtues of a bold attempt to bring difficult ideas to more general currency. Charles Strachan 